\title{
Aprendizagem e Jogos: diálogo com alunos do ensino médio-técnico
}

\author{
Myrna Cecília Martins dos Santos Amorim' \\ Eloiza Silva Gomes Oliveira" \\ Joel André Ferreira Santos"II \\ João Roberto de Toledo Quadros'
}

'Centro Federal de Educação Tecnológica Celso Suckow da Fonseca

(CEFET), Rio de Janeiro/RJ - Brasil "Universidade Estadual do Rio de Janeiro (UERJ), Rio de Janeiro/RJ - Brasil "'Universidade Federal Fluminense (UFF), Niterói/RJ - Brasil

RESUMO - Aprendizagem e Jogos: diálogo com alunos do ensino médio-técnico. Este artigo apresenta uma experiência de ensino-aprendizagem por meio de jogos digitais realizada com alunos do ensino médio-técnico de informática. A ideia é aproveitar as habilidades que os alunos possuem com jogos e mostrar como o desenvolvimento de jogos digitais pode auxiliar no ensino de algoritmos e programação de forma lúdica, disciplinas essenciais ao curso de informática, mas que possuem altos índices de reprovação e abandono do curso.

Palavras-chave: Ensino Médio-Técnico. Jogos Digitais. Algoritmos E Programação.

ABSTRACT - Learning and Digital Games: a dialogue with technical secondary education students. This paper presents an experience of teachinglearning through digital games with computer tech students. The goal is to use the students' skills of playing digital games while demonstrating how the game designing can support the teaching of algorithms and programming in an entertaining and lively manner. Although these disciplines are primary to this course and the basis of other subjects, their rates of failure and withdrawal are high.

Keywords: Technical Secondary Education. Digital Games. Algorithms and Programming.

Educação \& Realidade, Porto Alegre, v. 41, n. 1, p. 91-115, jan./mar. 2016. 91 http://dx.doi.org/10.1590/2175-623656109 


\section{Introdução}

Para ser educador nos dias de hoje, não basta somente ter conhecimento sobre sua área específica. O professor precisa ser um incentivador de conhecimento e fazer com que os alunos sejam motivados a pensar e a desenvolver suas habilidades e competências e não apenas ser aquele transmissor de informações.

Mattar (2010) escreve que o que se aprende hoje para as avaliações nas escolas são apenas palavras e mais palavras e, por consequência, a retenção do conhecimento por parte do aluno é naturalmente baixa. Eles sentam para assistir passivamente às aulas e não conseguem fazer conexão com a própria realidade, pois o que está sendo transmitido muitas vezes não faz sentido algum.

Resolver problemas, ter iniciativa, compartilhar, aprender, cooperar, colaborar, ser criativo, buscar inovação, ter senso crítico, tomar decisões (muitas vezes rápidas), usar a tecnologia, ter capacidade para buscar e filtrar os dados em informações úteis, entre outras, são habilidades que em geral não são ensinadas na escola, mas que são essenciais para a vida pessoal e profissional.

É sabido que a educação passa por transformações com a inserção de tecnologias de comunicação e informação (TIC) para realizar o processo de aprendizagem, mas por que ainda existe resistência? Por que as mudanças que são encontradas em tantas áreas não são verificadas também na escola?

Uma crítica bem humorada sobre essas mudanças é encontrada no livro A máquina das crianças (Papert, 2008). O livro inicia com uma parábola sobre a reação de um grupo de viajantes do tempo, composto de médicos e professores do ensino básico, oriundos do final do século XIX e que teriam a oportunidade de visitar o mundo um século depois. $\mathrm{O}$ autor acredita que o grupo de médicos provavelmente ficaria espantado com os avanços da medicina e dificilmente conseguiria exercer a sua profissão com os conhecimentos adquiridos em sua época. Já os professores poderiam entrar numa sala de aula e, mesmo desconhecendo alguns materiais, não teriam tanta dificuldade em prosseguir.

Está cada vez mais difícil desvincular tecnologia da educação, afinal o discente já chega à sala portando smartphones, tablets, notebooks e outros dispositivos. Mas e o professor'? Ele sente-se preparado para lidar com todos os recursos e ferramentas disponíveis e aplicá-las em seu trabalho?

Uma pesquisa realizada pelo Comitê Gestor da Internet no Brasil, denominada TIC Educação 2013 (Figura 1), mostra que os professores e alunos brasileiros utilizam cada vez mais tecnologia (computador e Internet) em suas atividades em sala de aula (Barbosa, 2014).

92 Educação \& Realidade, Porto Alegre, v. 41, n. 1, p. 91-115, jan./mar. 2016. 
Figura 1 - Recursos mais usados em sala de aula

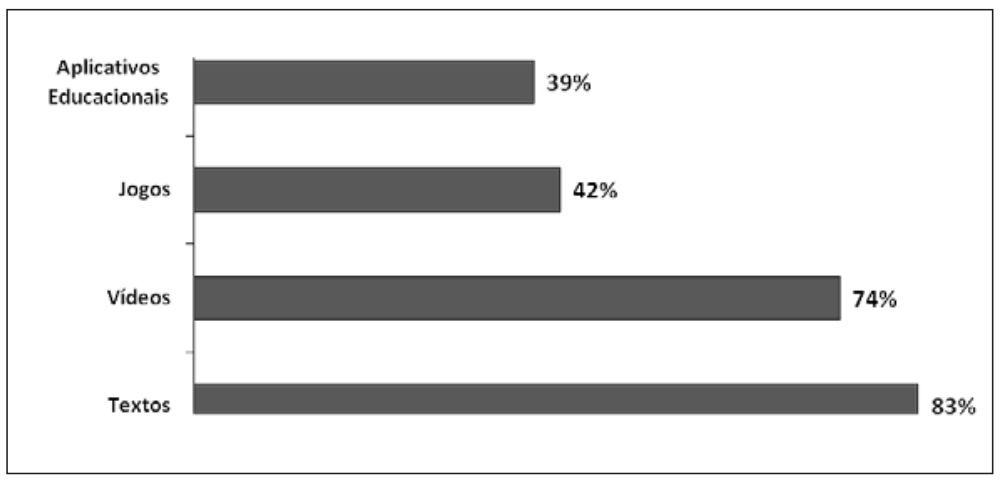

Fonte: TIC Educação 2013 - CETIC.BR / NIC.BR (Barbosa, 2014).

Todavia, ao realizar um estudo entre professores e indagar sobre quais dificuldades eram encontradas no uso das TIC no desenvolvimento do trabalho docente, Rosa (2013) verificou que três respostas se destacaram:

- falta de domínio no uso das tecnologias por parte dos docentes;

- número de aulas e quantidade de conteúdo a ser abordado durante o período;

- receio de não corresponder às expectativas dos discentes.

Logo, adequar os estilos de ensino dos professores aos estilos de aprendizagem dos alunos é um grande desafio. Kenski (2009, p. 103) afirma que:

\begin{abstract}
Um dos grandes desafios que os professores brasileiros enfrentam está na necessidade de saber lidar pedagogicamente com alunos e situações extremas: dos alunos que já possuem conhecimentos avançados e acesso pleno às últimas inovações tecnológicas aos que se encontram em plena exclusão tecnológica; das instituições de ensino equipadas com mais modernas tecnologias digitais aos espaços educacionais precários e com recursos mínimos para o exercício da função docente. O desafio maior, no entanto, ainda se encontra na própria formação profissional para enfrentar esses e tantos outros problemas.
\end{abstract}

Uma sugestão seria a integração entre os elementos pedagógicos, games $^{2}$ e a utilização de simulações, principalmente quando o aluno encontra dificuldade em assimilar o conteúdo transmitido (Aldrich, 2005).

A Figura 2 mostra a distinção, idealizada por Aldrich, entre os conceitos de simulação, games e pedagogia utilizando a ideia de elementos. 
Figura 2 - Diferenças e Semelhanças entre os Elementos

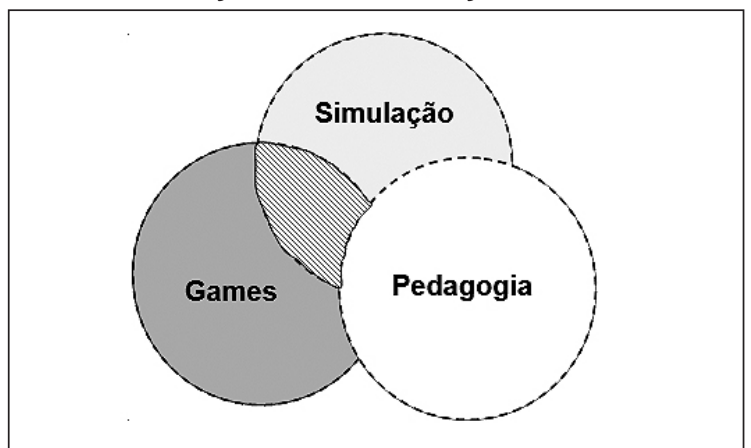

Fonte: Adaptado de Learning by Doing (Aldrich, 2005).

- Elementos de games oferecem a ideia de interação entre os atores, propiciando atividade ao sujeito em que ele se autoconstrói como ser singular e social, ao mesmo tempo que constrói o outro e o mundo, ampliando e solidificando a experiência de aprender.

- Elementos de simulações representam situações com o objetivo de estimular a prática e possibilitar transferência do aprendizado e de habilidades do mundo virtual para o mundo real.

- Elementos pedagógicos incluem os objetivos de aprendizagem e os motivos para decidir e construir uma simulação. Devem envolver os elementos de games e de simulações para garantir que 0 tempo do aluno seja utilizado de forma produtiva.

Segundo Aldrich (2005, p. 34), “[...] as pessoas aprendem melhor quando não sabem que estão aprendendo. [...] mesmo que seja útil" e esta é uma das características dos games: o jogador determina como aprende, afinal é livre para descobrir e criar arranjos de aprendizado que funcione melhor para ele.

Outra perspectiva em relação à aprendizagem baseada em jogos digitais está no conceito de desenvolvê-los, ou seja, aproveitar as disciplinas de programação e incentivar os alunos do ensino médio-técnico integrado ${ }^{3}$ a criarem seus próprios jogos, aplicando o conteúdo abordado nessas disciplinas.

A formação de conceitos é o resultado de uma atividade complexa, em que todas as funções intelectuais básicas, como atenção deliberada, memória lógica, abstração, capacidade para comparar e diferenciar, entre outras, tomam parte.

Segundo Vygotsky (1991), os conceitos novos e mais elevados transformam o significado dos conceitos inferiores, espontâneos ou cotidianos. Chama a atenção, no entanto, para o fato de que é necessário que o conceito espontâneo tenha alcançado certo nível de desenvolvimento para que o conceito científico correspondente seja internalizado. Dessa forma, ao criar um jogo, o aluno do ensino médio-técnico 
estará recebendo uma estimulação da sua zona de desenvolvimento proximal no sentido de alcançar a formulação de conceitos científicos a partir de conceitos espontâneos que já possui.

Para Vygotsky (1991, p. 93):

\begin{abstract}
A criança adquire consciência dos seus conceitos espontâneos relativamente tarde; a capacidade de defini-los por meio de palavras, de operar com eles à vontade, aparece muito tempo depois de ter adquirido os conceitos. Ela possui o conceito [...], mas não está consciente do seu próprio ato de pensamento. O desenvolvimento de um conceito científico, por outro lado, geralmente começa com sua definição verbal e com sua aplicação em operações não-espontâneas [...]. Poder-se-ia dizer que o desenvolvimento dos conceitos espontâneos da criança é ascendente (indutivo), enquanto o desenvolvimento dos seus conceitos científicos é descendente (dedutivo).
\end{abstract}

Esse é o principal objetivo deste artigo: mostrar como os jogos digitais podem ser utilizados no ensino e na aprendizagem das disciplinas de informática, principalmente aquelas que envolvem algoritmos ${ }^{4} \mathrm{e}$ programação, promovendo a aprendizagem significativa, estimulando a interação entre os atores e propiciando a formação de conceitos científicos.

\title{
Aprendizagem com Mediação das Tecnologias Digitais: desafios para os que ensinam
}

\section{Os que ensinam..}

Os cursos de formação de educadores em nível do ensino médio e do ensino superior têm uma longa e bela trajetória no cenário educacional do nosso país. Gerações de professores foram formadas e bem formadas pelas instituições que a isso se dedicaram.

Esta formação está calcada na competência e na capacidade do docente de decidir e de avaliar a sua prática de ensinar. Afinal, uma formação de qualidade é aquela que contribui para o desenvolvimento da formação do indivíduo. Contudo, nas últimas décadas, são crescentes os questionamentos e as propostas de reformulações e de novas políticas para essa formação e, com o advento e a expansão das TIC, esses questionamentos se avolumaram.

Ao lado de reivindicações justas e históricas, referentes à remuneração e às condições de trabalho, estão sempre presentes as que se referem à qualidade da formação docente, à inserção da tecnologia como recurso de mediação e de incentivo à interação na educação, ao letramento digital e à inclusão digital de professores e alunos. Não há como desconhecer que todo esse conjunto de fatores deve impactar o currículo dos cursos de formação de educadores. 
Freire (2009, p. 23) adaptou o conceito dos 6 Rs, proposto inicialmente pelo grande educador Paulo Freire (1983), à situação atual da prática docente impactada pelas TIC:

- Reculturação: criação de uma nova cultura escolar, diferente da tradicional, com profundas modificações das normas, habilidades, práticas, abordagens de ensino e de aprendizagem, do próprio sistema de avaliação, por exemplo.

- Reestruturação: mudança radical da organização escolar, atingindo até mesmo os papéis de todos os atores institucionais.

- Redimensionamento do tempo: revisão do tempo utilizado para a aprendizagem, flexibilizando o entendimento de aula, admitindo contextos virtuais, semipresenciais.

- Redefinição: revisão conceitual que dê base a novos conceitos de aula, sala de aula, interação, avaliação e formação de professores.

- Recolocação: admissão da existência de ambientes de aprendizagem fora dos limites escolares, de forma síncrona ou assíncrona (como, por exemplo, as redes sociais).

- Reequipagem: instrumentalização do professor para essas novas ferramentas e práticas.

Ainda assim, muito se tem escrito e debatido sobre a apropriação efetiva, crítica e reflexiva das tecnologias digitais pelos professores. Multiplicam-se políticas públicas e projetos governamentais que tomam por base a imprescindibilidade da inclusão das tecnologias na educação.

Ao mesmo tempo, nas escolas há professores com pouco domínio dos conteúdos que ministram e dificuldade de relacioná-los com a prática social dos alunos, trazendo ainda uma visão idealizada do magistério e do aluno perfeito, disciplinado, pleno de desejo de aprender; além da questão salarial, que é crônica, e da multiplicação de jornadas de trabalho. A divisão do trabalho no interior da escola persiste, assim como as práticas burocráticas, conservadoras e fragmentadoras.

Os alunos, por sua vez, chegam cada vez mais informados pelo acesso a fontes diversas, principalmente a internet. Essas informações são muitas vezes confusas, nem sempre corretas e torna-se necessário que sejam triadas, organizadas e confrontadas com o saber sistematizado universal, com a herança cultural da comunidade em particular, e da humanidade em geral. Essa geração traz também uma inédita habilidade para lidar com as tecnologias de informação e comunicação, novas linguagens, habilidades cognitivas e estilos de aprendizagem.

Prensky (2001) fala dos professores como imigrantes digitais: aqueles que nasceram vinte anos antes de o conceito ser criado por ele. Pessoas que tem que se adaptar a estas mudanças tecnológicas que ocorrem de maneira rápida e intensa.

96 Educação \& Realidade, Porto Alegre, v. 41, n. 1, p. 91-115, jan./mar. 2016. 
Pelo fato dos imigrantes digitais não terem nascido e sido criados nessa sociedade incrivelmente tecnológica de hoje, não veem com naturalidade esses avanços, diferentemente de como os nativos digitais as veem. Por mais que muitos desses imigrantes se adaptem de maneira rápida ainda continuam com vícios comportamentais da sua época em que a tecnologia não era preponderante como atualmente.

Para o autor, essa característica dos imigrantes é comparada ao sotaque que uma pessoa demonstra ao aprender uma nova língua, que não é o seu idioma nativo. Enquanto que para os nativos tudo é natural e do cotidiano, os imigrantes precisam se adaptar e aprender a lidar a este novo mundo no qual estão inseridos.

Já Palfrey e Gasser (2011) os chamam de colonizadores digitais, pessoas mais velhas que estão na era digital desde o seu início, mas cresceram em um mundo analógico e vêm contribuindo para a evolução tecnológica. Apesar disso, usam as tecnologias, mas baseados nas formas tradicionais e analógicas de interação. Como então superar este gap entre professor e aluno?

\title{
A Inserção das Tecnologias na Prática Docente
}

A inclusão digital do professor aparece como uma das principais formas de superação do abismo formado. Então, como estabelecer a inclusão digital a partir do quadro da formação docente atual? Como fazer com que a inclusão digital se expresse em mudanças na prática docente, no cotidiano dos processos de ensino e aprendizagem?

Para o primeiro questionamento, entende-se inclusão digital da mesma forma que Warschauer (2006): é necessário não só dar acesso ao hardware, mas também disponibilizar recursos físicos, digitais, humanos, sociais e relacionais. Assim, conteúdo, linguagem, alfabetização e educação, comunidade e estrutura institucional devem ser levados em conta para dar acesso significativo às tecnologias digitais.

Para De Luca (2004, p. 9), “[...] a inclusão digital deve favorecer a apropriação da tecnologia de forma consciente, que torne o indivíduo capaz de decidir quando, como e para que utilizá-la”. Não se trata apenas de fornecer conectividade e doar computadores, ou ainda realizar cursos de capacitação que aumentem a proficiência para lidar com as tecnologias. O essencial, segundo Pellanda (2005, p. 36), é que:

\begin{abstract}
[...] a relação ser humano/tecnologias digitais pode servir de dispositivo cognitivo ontológico para que os seres humanos possam se pensar como sujeitos de seu próprio processo de viver e, então, possam se considerar como um nó nessa grande rede humana construindo seus próprios instrumentos de inclusão.
\end{abstract}

Além de fornecer os recursos tecnológicos necessários, é indispensável provocar os cursos de formação docente a profundas mu- 
danças que permitam a utilização das tecnologias no próprio processo de formação, como ferramentas de interação e mediação pedagógica. Conforme Behrens (1995, p. 15), “[...] neste momento de globalização mundial, continuamos a tratar a formação do professor com discursos vazios de uma prática apropriada e significativa. Reverter este papel perante a sociedade é uma tarefa árdua”. Essa formação deve atender as mesmas exigências dos demais setores da sociedade: formar um ser autônomo, não um receptor de informações pré-moldadas, repetidor de modelos estáticos em sua atuação profissional.

Quanto à segunda questão, acredita-se ainda na atualidade dos cinco estágios evolutivos propostas pelo Projeto ACOT ${ }^{5}$ (Apple Classrooms of Tomorrow) para a incorporação das tecnologias digitais à prática docente: entrada, adoção, adaptação, apropriação, invenção. A tabela 1 mostra, de forma resumida, esses estágios.

Tabela 1 - Estágios Evolutivos das TIC

\begin{tabular}{|c|c|}
\hline ESTÁGIO & EXEMPLOS DO QUE FAZEM OS PROFESSORES \\
\hline Entrada & $\begin{array}{l}\text { Aprendem as habilidades básicas para lidar com Tecnologias da } \\
\text { Informação e Comunicação (TIC). }\end{array}$ \\
\hline Adoção & $\begin{array}{l}\text { Usam as TIC, ainda mesclando-as com as práticas pedagógicas } \\
\text { tradicionais. }\end{array}$ \\
\hline Adaptação & $\begin{array}{l}\text { Integram as TIC às atividades de sala de aula, principalmente } \\
\text { com foco na produção dos alunos. }\end{array}$ \\
\hline Apropriação & $\begin{array}{l}\text { Focalizam o trabalho cooperativo, projetos de aprendizagem } \\
\text { e interdisciplinaridade, incorporando as TIC quando elas são } \\
\text { necessárias, como uma entre muitas ferramentas. }\end{array}$ \\
\hline Invenção & $\begin{array}{c}\text { Descobrem novas formas de utilizar as ferramentas e combinam } \\
\text { múltiplas tecnologias. }\end{array}$ \\
\hline
\end{tabular}

Fonte: Adaptado - Projeto ACOT (Dwyer; Ringstaf; Sandholtz, 1990).

É possível perceber, por esta sequência de estágios, que o esperado é uma incorporação progressiva das tecnologias digitais, no ritmo possível ao professor, em que ele se familiariza com elas e abandona aos poucos certas práticas mais tradicionais, chegando à autoria e à autonomia na utilização das mesmas como ferramentas na prática cotidiana. Não se trata simplesmente de incorporar as TIC à formação e à prática docente de maneira açodada, sem que haja definições claras de políticas de formação.

\section{E os que Aprendem?}

Para melhor entendimento dos jovens que chegam hoje às escolas, intensamente imersos nos meios tecnológicos, será utilizado neste texto a expressão nativos digitais, idealizada por Marc Prensky em 2001. 
Este termo foi empregado pela primeira vez no artigo Digital Natives, Digital Immigrants, no qual trata de um perfil tecnológico das crianças e jovens ao redor do mundo.

Assim como Prensky (2001), outros autores também criaram termos para as gerações. Segundo Tapscott (1999):

- Baby boomers (entre 1946 a 1964): é a geração que acompanhou uma verdadeira revolução nas telecomunicações, principalmente com a ascensão da televisão. Para os boomers a televisão era a inovação do século e os eventos históricos que marcaram esse período foram assistidos nos lares graças a esse novo dispositivo;

- Geração X (de 1965 até o final dos anos 1970): geração que tinha a televisão como um aparato comum no seu lar, por isso, tornou-se uma geração extremamente orientada para a mídia. Durante a popularização dos computadores e da internet, eram adultos e foram assimilando essa realidade com certa facilidade;

- Geração $Y$ (a partir de 1980): esta geração recebeu diversas nomenclaturas como geração net, millennials (Howe; Strauss, 2000), net generation ou, simplesmente, N-Gen: esta geração se diferencia das outras principalmente por estar imersa num ambiente virtual. São crianças e jovens que cresceram à frente do videogame, conviveram com a internet, o computador doméstico, o celular e com outros dispositivos tecnológicos.

Para Prensky, nativos digitais são todas aquelas pessoas que nasceram nos últimos vinte anos e chegam a um mundo que está rodeado pelas TIC. Ao se depararem desde cedo com esse contexto de uma vida tecnológica enxergam essas tecnologias como algo natural, ou seja, do próprio cotidiano.

Sendo assim, passam a assimilar com facilidade maior o desenvolvimento tecnológico, pois conseguem se adaptar a essas trocas na mesma rapidez que elas ocorrem. Como a tecnologia é algo presente desde o momento em que eles se inserem no contexto social, usar o celular, jogar videogame ou jogos digitais, ficar online, acessar redes sociais, entre outras milhões de coisas que fazem, são algo natural, já que não conheceram um mundo sem isso.

Veen e Vrakking (2009) falam de uma nova geração que adotou a tecnologia e com ela desenvolveu estratégias para viver e para aprender, que cresceu e descobriu o mundo através de uma multiplicidade de canais de televisão, jogos digitais, tablets, websites, blogs e celulares, e que também explorou as implicações do seu comportamento para aprender. A esta geração chamam Homo Zappiens.

Segundo os autores, os Homo Zappiens são processadores ativos de informação, capazes de solucionar uma variedade de problemas usando estratégias de jogos e uma comunicação eficaz - aprendem jogando, como em um jogo exploratório. 
Estes nativos da chamada era digital dão muito valor ao compartilhamento de informações, principalmente por meio das redes sociais, blogs e microblogs. Tudo isso podendo ser acessado por um dispositivo móvel ou por computadores pessoais. Estes meios, porém, não servem apenas para isso, mas também para avaliar produtos, pessoas, para a mostra de serviços, dando uma resposta em tempo real, pois podem ser acessados instantaneamente, bastando estar conectados à Internet.

Essas características dos jovens de hoje mostram que eles aprendem de uma forma diferente da que seus pais aprendiam no passado. Esse mundo digital no qual estão inseridos é atrativo para ser explorado, e é assim que os nativos digitais aprendem a utilizar todas as ferramentas disponíveis.

Eles aprendem tudo explorando, tentando, mexendo; não leem manuais, aprendem compartilhando. Com essa sociedade globalizada e digital, tem-se uma rápida e fácil obtenção de conhecimento e de aprendizagem; com isso, eles não esperam mais a informação e o conhecimento virem até eles através de seus pais ou professores, mas vão atrás da informação em um mundo online e virtual, através da pesquisa em sites e nas redes sociais (Carvalho; Oliveira; Silva, 2015).

Mattar (2010, p. 10) afirma que os jovens de hoje não aprendem numa estrutura linear como era antigamente, “[...] eles possuem mentes hipertextuais”. Ele associa estas características de busca de conhecimento com os comportamentos percebidos nos jogos, também de grande preferência pelos jovens: "[...] o aprendizado necessita de motivação para um envolvimento intenso, o que é atingido pelos games" (Mattar, 2010, p. 13).

Conforme Tapscott (1999, p. 95-117), existem oito características da net generation que mostram como os alunos de hoje aprendem. São elas:

a) Liberdade: desejam flexibilidade de opções nas situações de aprendizagem.

b) Customização: desenvolvimento de um aprendizado próprio, segundo suas necessidades e interesses.

c) Investigação: tendência a questionar e investigar a informação obtida.

d) Integridade: relacionada aos aspectos éticos do comportamento.

e) Colaboração: capacidade de criar conhecimento com foco coletivo, em equipe.

f) Entretenimento: desejam que o aprendizado seja prazeroso, divertido.

g) Velocidade: querem aprender rapidamente, de forma objetiva e prática.

h) Inovação: estímulo à apresentação de soluções novas, diferentes.

100 Educação \& Realidade, Porto Alegre, v. 41, n. 1, p. 91-115, jan./mar. 2016. 
Eles são, acima de tudo, críticos e desejosos de autoria e protagonismo em relação à própria aprendizagem, o que remete ao conceito de cultura participativa, enunciado por Jenkins (2009, p. 378): “[...] cultura em que fãs e outros consumidores são convidados a participar ativamente da criação e da circulação de novos conteúdos” (2009, p. 378).

A cultura participativa, nas palavras de Jenkins (2009, p. 30), “[...] contrasta com noções mais antigas sobre a passividade dos espectadores dos meios de comunicação".

Faz pensar também na inteligência coletiva proposta por Lèvy (2004, p. 20):

\begin{abstract}
[...] uma inteligência distribuída por toda a parte, incessantemente valorizada, coordenada em tempo real, que resulta em mobilização efetiva das competências. Acrescentemos à nossa definição este complemento indispensável: a base e o objetivo da inteligência coletiva são o reconhecimento e o enriquecimento mútuo das pessoas, senão o culto de comunidades fetichizadas ou hipostasiadas. Uma inteligência distribuída por toda parte: tal é o nosso axioma inicial. Ninguém sabe tudo, todos sabem alguma coisa, todo o saber está na humanidade.
\end{abstract}

Carniello, Rodrigues e Moraes (2010) falam que os nativos digitais, diferentemente dos imigrantes, pelo fato de fazerem do mundo digital uma parte da sua vida cotidiana, conseguem ser multifuncionais. Eles se divertem jogando, conversam e se relacionam através de programas de mensagens instantâneas (como o Skype, o Hangouts e os chats do Facebook), falam de sua vida, sonhos e desejos, assim como das experiências nas redes sociais. Debatem sobre política, baixam músicas e filmes, utilizam o espaço para divulgar algo e ainda conseguem utilizar as TIC para pesquisas acadêmicas e aprendizado.

Os nativos digitais são caracterizados pela capacidade de absorver diversas informações ao mesmo tempo, simultaneamente, em um ritmo frenético. Seu raciocínio e pensamento muitas vezes podem ser comparados a um hipertexto, uma vez que não é linear, mas conduzido por cliques.

É nesse ritmo de hipertexto, nessa velocidade digital, que os alunos dessa geração chegam à sala de aula e encontram os professores, às vezes imigrantes digitais, mas às vezes pouco acostumados ao uso das TIC, e a escola, que parece estar desconectada do mundo deles.

Outro aspecto que vale ressaltar é que os nativos digitais são seletivos no quesito absorção do conhecimento. Neste mundo em que as informações surgem de maneira muito rápida e é imensa a quantidade disponível, nem tudo é importante. Logo, é necessário se concentrar naquilo que de fato é fundamental para eles e, quando algo tem pouca relevância, é descartado rapidamente, sem se dar a devida atenção. 
Tori (2010, p. 218), ao falar sobre nativos e imigrantes digitais, diz que os estudantes, nativos digitais, são ensinados por professores imigrantes, oriundos de uma cultura pré-internet e que muitas vezes não valorizam ou trabalham as características desses alunos.

O cérebro dos nativos se desenvolveu de forma diferente em relação às gerações pré-internet. Eles gostam de jogos, estão acostumados a absorver (e descartar) grande quantidade de informações, a fazer atividades em paralelo, precisam de motivação e recompensas frequentes, gostam de trabalhar em rede e de forma não linear.

Além disso, para Prensky (2012, p. 60), “[...] os nativos estão acostumados a receber informações com muito mais rapidez do que aquela que os imigrantes sabem passá-las".

E conclui o autor:

Não importa quanto os Imigrantes desejem, os Nativos Digitais não voltarão atrás. Em primeiro lugar, não funcionaria: seus cérebros provavelmente já possuem padrões diferentes dos nossos. Em segundo lugar, seria um insulto a tudo que sabemos sobre migração cultural. [...] Adultos Imigrantes inteligentes aceitam a ideia de que não sabem tanto a respeito deste novo mundo e aproveitam a ajuda de seus filhos para aprender e integrar-se. Imigrantes não tão inteligentes [...] passam a maior parte de seu tempo lamentando o quanto as coisas eram boas no velho mundo (Prensky, 2012, p. 60).

\section{Jogos Digitais e a Aprendizagem}

Conforme Prensky (2012), a aprendizagem baseada em jogos está de acordo com as necessidades e os estilos de aprendizagem da geração atual e das futuras gerações. É motivadora, divertida e versátil, capaz de ser adaptada a quase todas as disciplinas, informações ou habilidades, mas só acontece quando tanto o envolvimento quanto a aprendizagem são altos (Figura 3).

\section{Figura 3 - Relação entre o Envolvimento e a Aprendizagem}

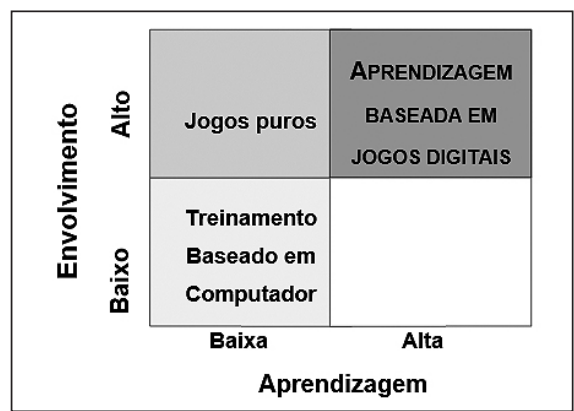

Fonte: Aprendizagem Baseada em Jogos Digitais (Prensky, 2012, p. 212). 
No livro, o autor propõe quatro ideias gerais para os docentes:

1. Discutir sobre os jogos que são usados fora da sala de aula;

2. Utilizar os princípios dos bons jogos digitais no próprio ensino;

3. Jogar em sala os jogos digitais produzidos especificamente para educação;

4. Jogar em sala jogos digitais comerciais.

A tabela 2 mostra alguns bons exemplos de jogos digitais comerciais que podem ser utilizados nas mais diversas disciplinas.

Tabela 2 - Exemplos de Jogos Digitais

\begin{tabular}{|l|l|}
\hline \multicolumn{1}{|c|}{ Jogos } & \multicolumn{1}{c|}{ TEMA } \\
\hline Age of Empires & História e Geografia \\
\hline Angry Birds & Física e Matemática \\
\hline Assassin's Creed & História \\
\hline Brain Age & Raciocínio lógico \\
\hline Civilization & Gerenciamento estratégico \\
\hline God of War & Mitologia grega \\
\hline Greenpeace WeAtheR & Meio ambiente e Ecologia \\
\hline Guitar Hero & Música \\
\hline Hora do Rush & Resolução de problemas \\
\hline I Love Traffic & Educação no trânsito \\
\hline LetterBlox & Inglês, vocabulário, ortografia e memorização \\
\hline $\begin{array}{l}\text { Phoenix Wright: Ace } \\
\text { Attorney }\end{array}$ & Direito \\
\hline Portal & Física \\
\hline SimCity & Administração de cidades \\
\hline Spore & Biologia \\
\hline
\end{tabular}

Fonte: Adaptado do livro Games em Educação (Mattar, 2010).

Como exemplo de aplicação em sala de aula, considere o jogo Hora do Rush ${ }^{6}$ (Figura 5), com versões para smartphones, tablets e computadores. Este jogo foi usado como introdução à disciplina de algoritmos para abordar a questão da resolução de problemas (Figura 4). 
Figura 4 - Esquema para Resolução de Problemas

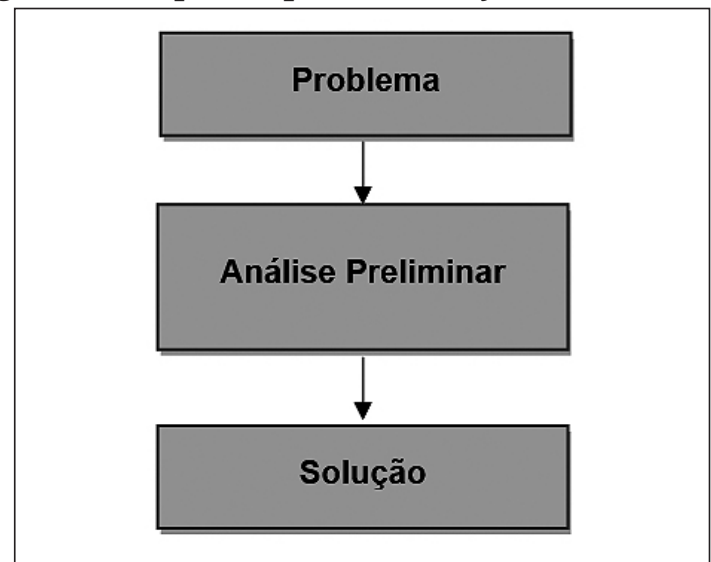

Fonte: Adaptado da resolução de algoritmos - Algoritmos (Cormen et al., 2009).

Figura 5 - Jogo Hora do Rush

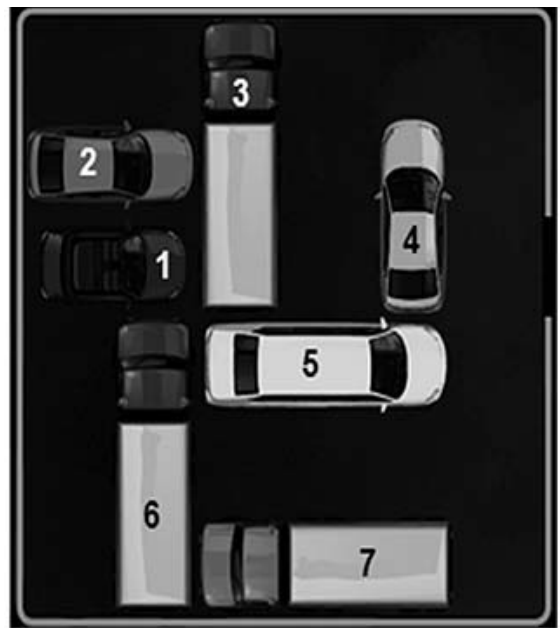

Fonte: Tela capturada do jogo Hora do Rush (versão para smartphones).

O jogo Hora do Rush tem como principal objetivo sair com o carro vermelho $^{7}$ (1) da garagem seguindo as regras: o jogador pode mexer os outros carros (obstáculos), prestando atenção em movimentar na horizontal apenas os carros que estão na horizontal e na vertical aqueles que estão na vertical.

Apesar de simples, os jogadores tentam resolver o problema usando a técnica tentativa e erro, executando vários movimentos desnecessários. Após algumas tentativas, o problema é resolvido, mas existe uma forma de aperfeiçoar a solução. E é neste momento que o papel do professor se torna importante: ser mediador e ensinar ao aluno como proceder na resolução de um problema. 
De acordo com a Figura 4, para resolver um problema é necessário realizar uma análise preliminar, algo que não é feito com sucesso na técnica tentativa e erro. Para fazer a análise e chegar numa possível solução, pode-se utilizar outra estratégia (empregada em diversas disciplinas do curso, como algoritmos e estruturas de dados) denominada divisão e conquista: divida o problema original, que é retirar o carro vermelho (1) da garagem, em problemas menores (subproblemas). Resolva cada subproblema e depois combine as soluções obtidas até chegar à solução final (global). Será que fica mais simples?

Aplicando a técnica na Figura 5, é possível dividir o problema retirar o carro vermelho - em subproblemas. Para resolver os subproblemas, basta responder às perguntas: consigo movimentar o carro vermelho (1) de imediato? Não. Qual é o obstáculo? Caminhão vermelho (3). Posso movimentar o caminhão vermelho e retirar o carro vermelho? Não. Qual é o obstáculo? Carro branco (5). Se movimentar o carro branco, consigo mexer o caminhão e finalmente retirar o carro vermelho? Ainda não. Qual é o obstáculo? Caminhão verde (7). Movimentando o caminhão verde e os outros obstáculos citados, posso sair com o carro vermelho? Não, pois o carro amarelo (4) atrapalha a saída. Andar com o carro amarelo e realizar as movimentações anteriores resolve? Se a reposta for afirmativa, então agora basta executar os movimentos analisados (solução dos subproblemas) e retirar o carro vermelho (problema original). Observe que ao fazer uma análise antes, resolve-se o problema sem alterar a cena e realizar movimentos desnecessários.

Esta técnica pode ser empregada em qualquer fase do jogo, basta seguir o diagrama de atividades da Figura 6. Além disso, mostra uma importante estratégia na resolução de problemas que pode ser utilizada na disciplina de algoritmos.

Figura 6 - Diagrama de Atividades para o jogo Hora do Rush

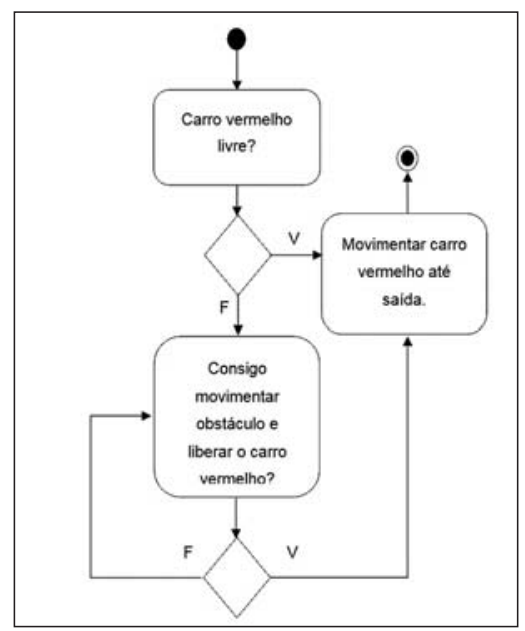

Fonte: Elaborado pelos autores. 
Após aplicá-la em sala, muitos alunos percebem como fica mais simples passar para as outras fases e aprendem um método eficaz na solução do problema, ou seja, faça uma análise preliminar: identifique qual é o principal objetivo do problema proposto (saída), o que deve ser calculado (processamento) e qual(is) é(são) o(s) dado(s) inicial(is) (entrada). Com isso, o aluno acabou de resolver um algoritmo, basta agora explicar como especificar a sua estrutura e apresentar a solução final. Este esquema condiz com o funcionamento básico de um computador baseado na arquitetura de Von Neumann, como mostra a Figura 7.

\section{Figura 7 - Esquema Básico do Funcionamento de um Computador}

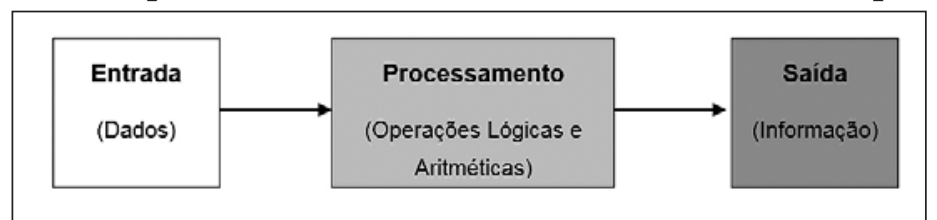

Fonte: Introdução à Organização de Computadores (Monteiro, 2007, p. 2).

Entretanto, mesmo usando essa estratégia, alguns alunos sentem-se frustrados, pois continuam com dificuldades em aprender algoritmos e programação. Isso ocorre principalmente por se tratar de disciplinas que precisam de raciocínio lógico, de compreensão dos conceitos mostrados em aula, de abstração e da capacidade de entender e de utilizar as linguagens de programação. Esta dificuldade acaba refletindo no alto índice de reprovação nas primeiras fases dos cursos de informática e consequentemente na alta taxa de evasão.

A tabela 3 apresenta um estudo realizado pelo coordenador do curso de informática entre os anos de 2003 ( $2^{\circ}$ semestre) a 2014 ( $1^{\circ}$ semestre), que retrata a taxa de evasão: quantidade de alunos que terminaram o curso dividido pelo total de alunos que entraram.

Tabela $3^{8}$ - Taxa de Evasão de um curso técnico de informática

\begin{tabular}{|c|c|c|c|c|c|c|c|c|c|}
\hline ENTRADA & $2003 / 2$ & $2004 / 1$ & $2004 / 2$ & $2005 / 1$ & $2005 / 2$ & $2006 / 1$ & $2006 / 2$ & $2007 / 1$ & $2007 / 2$ \\
\hline CONCLUSÃO & $2006 / 1$ & $2006 / 2$ & $2007 / 1$ & $2007 / 2$ & $2008 / 1$ & $2008 / 2$ & $2009 / 1$ & $2009 / 2$ & $2010 / 1$ \\
\hline Manhã & $68,29 \%$ & $85,37 \%$ & $61,90 \%$ & $94,74 \%$ & $57,89 \%$ & $64,58 \%$ & $62,50 \%$ & $70,73 \%$ & $47,22 \%$ \\
\hline Tarde & $43,90 \%$ & $65,22 \%$ & $56,82 \%$ & $53,85 \%$ & $55,56 \%$ & $0,00 \%$ & $0,00 \%$ & $0,00 \%$ & $0,00 \%$ \\
\hline ENTRADA & $2008 / 1$ & $2008 / 2$ & $2009 / 1$ & $2009 / 2$ & $2010 / 1$ & $2010 / 2$ & $2011 / 1$ & $2011 / 2$ \\
\hline CONCLUSÃO & $2010 / 2$ & $2011 / 1$ & $2011 / 2$ & $2012 / 1$ & $2012 / 2$ & $2013 / 1$ & $2013 / 2$ & $2014 / 1$ \\
\hline Manhã & $41,03 \%$ & $31,43 \%$ & $51,43 \%$ & $37,14 \%$ & $61,76 \%$ & $35,48 \%$ & $48,72 \%$ & $54,05 \%$ \\
\hline Tarde & $68,42 \%$ & $74,36 \%$ & $91,67 \%$ & $85,19 \%$ & $87,18 \%$ & $81,25 \%$ & $77,78 \%$ & $84,00 \%$ \\
\hline
\end{tabular}

Fonte: Elaborado pelos autores.

A primeira linha da tabela indica o ano/semestre de entrada no curso, a segunda linha o ano/semestre de conclusão (considerando seis 
semestres) e a terceira e quarta linhas destacam a taxa de evasão no período. A tabela mostra, por exemplo, na primeira coluna, que $68,29 \%$ dos alunos do turno da manhã e $43,90 \%$ dos alunos do turno da tarde não concluíram o curso. Ou ainda, por outra perspectiva, pode-se verificar que no primeiro semestre de 2004 no turno da manhã, dos 41 alunos que entraram, apenas seis terminaram o curso em 2006, ou seja, apenas $14,63 \%$ do total de alunos (85,37\% de evasão).

Apesar da tabela incluir na taxa de evasão a quantidade de alunos reprovados, os que desistiram e os que trancaram o curso e não ter dados específicos sobre a reprovação na disciplina de programação, ainda mostra dados alarmantes. Por isso, na tentativa de minimizar a quantidade de evasão, os docentes se dedicam em buscar técnicas e ferramentas que incentivem a permanência dos alunos e, como muitos deles desistem nos períodos iniciais, busca-se uma solução para tornar o ensino e a aprendizagem de programação mais atraente e prazerosa, diminuindo a resistência em seu aprendizado (Papert, 2008). Uma das técnicas possíveis consiste em ensinar programação a partir da codificação de jogos (Quadros et al., 2013; Schocair et al., 2012).

\section{Uma Experiência de Sala de Aula: falam os jovens}

De acordo com Arruda (2014), o desenvolvimento de um jogo é um processo estimulante, desperta o interesse do aluno e permite a transferência de conhecimento por meio de associações, conclusões, deduções e seleções. O aluno codifica os programas e visualiza os resultados, tornando o processo mais concreto. A criação do jogo desenvolve a habilidade de trabalhar em equipe, pois é necessário discutir estratégias, cenários, pontos de vista diferentes (Grübel; Bez, 2006), além de possibilitar a assimilação de conteúdos vistos no decorrer do curso, pois o aluno precisa analisar, planejar, modelar e criar. Como resultado, pode-se observar:

- Processo de aprendizado mais agradável;

- Entusiasmo ao ver o programa (jogo) pronto;

- Aumento da interação entre alunos e entre professor-aluno;

- Mais interesse nas disciplinas de programação;

- Aumento da capacidade de retenção do conteúdo;

- Utilização de conceitos mais complexos do que os ensinados em aula;

- Desenvolvimento em linguagens de programação diferentes das abordadas em sala;

- Crescimento no interesse na participação de grupos de pesquisa.

Para iniciar o processo de aprendizagem de programação e de criação de um jogo, pode-se utilizar um editor (Figura 8) denominado 
Scratch (MIT, 2014), que foi desenvolvido pelo grupo Lifelong Kindergarten no Media Lab do MIT (Massachusetts Institute of Technology). É um software gratuito e foi projetado visando o aprendizado e a educação. A ideia é aprender a pensar de maneira criativa, refletir de maneira sistemática e trabalhar de forma colaborativa. $\mathrm{O}$ aluno pode criar $g a$ mes, aprender os conceitos iniciais de programação, matemática, desenho, etc., além de adquirir as habilidades essenciais discutidas no início deste artigo, como colaboração, compartilhamento de informações, criatividade, tomada de decisões e resolução de problemas, como se estivesse brincando (MIT, 2014; Mata et al., 2013; Mattar, 2010; Mendonça Neto, 2013; Pereira; Medeiros; Menezes, 2012).

Figura 8 - Página Inicial do Editor Scratch ${ }^{9}$

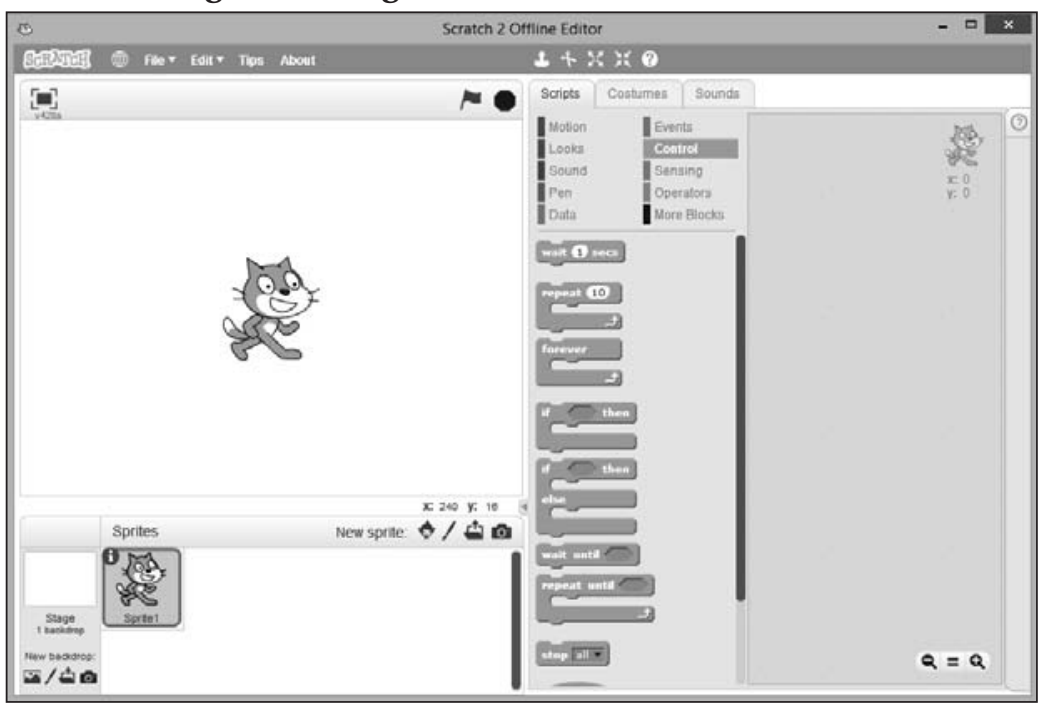

Fonte: Tela capturada do Editor Scratch (versão offline).

O Scratch foi utilizado em 2014 com os alunos do primeiro ano do ensino médio-técnico integrado do curso de informática, onde eles têm o primeiro contato com a programação através do algoritmo.

Para incentivá-los a aprender algoritmos, foi feita uma proposta à turma de criar jogos usando o Scratch com o contexto vinculado a alguma disciplina do ensino médio.

Foram implementadas algumas propostas e estas foram exibidas na feira técnica em outubro de 2014. Dois desses trabalhos foram premiados na feira, o que motivou ainda mais os alunos a aprender programação. Quatro alunos fizeram trabalhos relacionados à biologia, outros quatro à química e dois à filosofia. Como esta foi a primeira experiência, os alunos ficaram à vontade na escolha do tema e na criação da aplicação.

108 Educação \& Realidade, Porto Alegre, v. 41, n. 1, p. 91-115, jan./mar. 2016. 
Além do primeiro ano, a estratégia de trabalhar na criação de jogos foi proposta para os alunos do quinto período. Como estes alunos possuem maior experiência em programação, eles desenvolveram os jogos usando a linguagem Java, que estava sendo ensinada a eles, juntamente com a interface gráfica do usuário (GUI - Graphical User Interface). Aproveitando a oportunidade, eles criaram a documentação do jogo usando a UML (Unified Modeling Language), possibilitando a interdisciplinaridade, ou seja, a interação entre duas disciplinas: programação e modelagem computacional. Os alunos compartilharam as experiências, trabalharam em grupo e aprenderam os novos conceitos de maneira prazerosa, em vez da avaliação por meio de provas escritas ou implementadas no computador.

Para realizar o trabalho, os alunos do quinto período foram separados em duplas e cada uma delas iniciou o projeto com uma proposta de jogo. Após essa fase, os alunos realizaram a modelagem computacional e iniciaram o desenvolvimento do game, aproveitando o espaço da aula para tirar as dúvidas, interagir e trocar experiências.

Ao final, os trabalhos criados foram apresentados aos colegas de classe e ficaram expostos na feira técnica que acontece anualmente na escola como forma de incentivo à pesquisa, algo que tem gerado expectativa e motivação entre os alunos.

A escolha do tema e do jogo é livre e a cada período surgem inúmeras ideias. Em 2013 foram desenvolvidos quatro jogos (Figura 9): o Matemória (a) que é baseado em um jogo da memória e que utiliza conceitos da matemática. Sua finalidade é promover a diversão através de conhecimentos matemáticos e estimular o raciocínio lógico; o CupMatch (b) inspirado nos famosos jogos Candy Crush e Bejeweled e na Copa do Mundo de 2014 realizada no Brasil. É um jogo estilo puzzle, que tem como objetivo combinar pelo menos três peças iguais (em linha e/ou coluna) que são agrupadas e descartadas. Quando o jogador consegue levar as seis taças da seleção, que, inicialmente, estão na primeira linha à última linha do campo, então o jogo é finalizado; o Liga 4 (c) baseado no jogo Connect Four e que é uma espécie de jogo da velha. Consiste em fichas vermelhas e amarelas e um tabuleiro bilateral e vertical. $\mathrm{O}$ objetivo do jogo, que é disputado em dupla, é ir adicionando as fichas até que um dos jogadores consiga posicionar quatro fichas de mesma cor numa linha que pode ser na horizontal, na vertical ou na diagonal, mas, ao mesmo tempo, impedir que o adversário consiga atingir este objetivo; e finalmente, o Mastermind (d) ou Senha, como é conhecido no Brasil, que é um clássico jogo de raciocínio lógico e que consiste na adivinhação de um código secreto de cores, composto por quatro cores distintas. O jogador possui um número limitado de tentativas para adivinhar a senha, e a cada senha testada por ele são indicadas quantas das cores que ele combinou estão de fato no código secreto e quais destas estão em suas respectivas posições. Após atingir o limite de tentativas, caso o jogador não consiga adivinhar a senha, ela é revelada e o jogo é finalizado.

Educação \& Realidade, Porto Alegre, v. 41, n. 1, p. 91-115, jan./mar. 2016. 
Figura 9 - Jogos Desenvolvidos pelos Alunos do 5ํㅜㄹodo do Curso Técnico de Informática em 2013

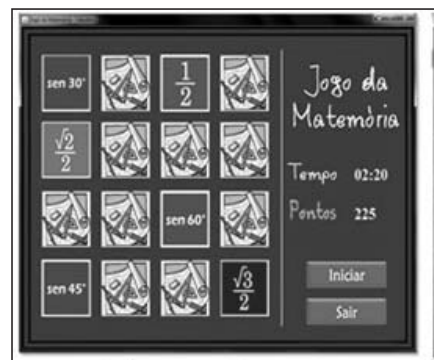

(a) Matemória

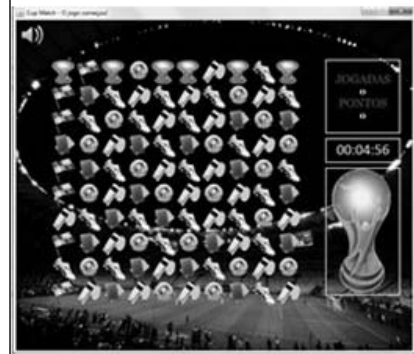

(b) CupMatch

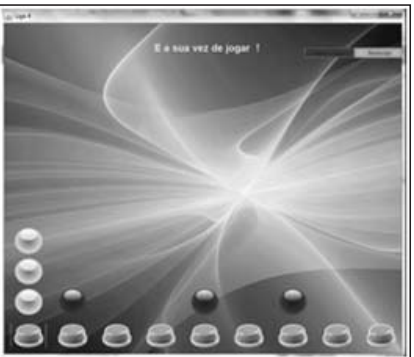

(c) Liga 4

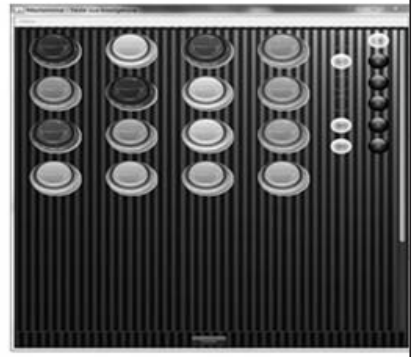

(d) Mastermind

Fonte: Telas capturadas dos jogos (elaborado pelos autores).

No primeiro período de 2014, foram desenvolvidos os jogos (Figura 10): MaraJoel Bank Simulator (e), que é inspirado no clássico Banco Imobiliário, mas usando como cenário a escola técnica; uma versão parecida do PacMan (f), onde é possível escolher o labirinto e a quantidade de fantasmas; um jogo similar ao Space Invaders e outro parecido com a batalha naval (os dois últimos não estão na figura).

Figura 10 - Jogos Desenvolvidos pelos Alunos do $5^{\circ}$ Período do Curso Técnico de Informática em 2014

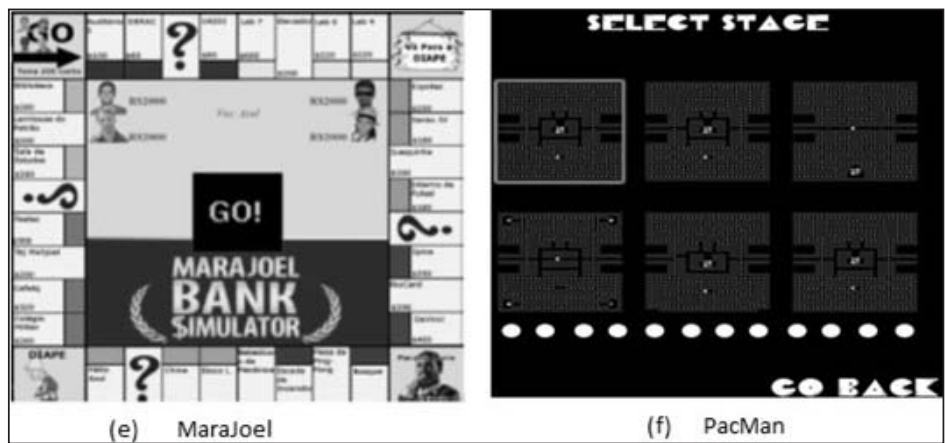

Fonte: Telas capturadas dos jogos (elaborado pelos autores). 
Apesar de ainda não ter uma metodologia específica para avaliar os resultados obtidos e realizar uma comparação entre ensinar o conteúdo, aplicar prova escrita ou implementada no computador e dar uma nota, observou-se maior interesse por parte dos alunos em aprender a nova linguagem de programação, menor quantidade de ausência em aula, maior interação entre os alunos e entre alunos-professor, tornando as aulas mais descontraídas.

Com o desenvolvimento do jogo e a exposição do trabalho, os alunos buscaram novas informações e não se contentaram apenas com os conceitos vistos. Notou-se, também, através dos trabalhos apresentados, que eles empregaram estruturas de dados mais complexas e eficientes daquelas que foram ensinadas, trabalharam de forma cooperativa e conseguiram entender, aplicar e relacionar os conteúdos das disciplinas estudadas no decorrer dos períodos.

\section{Considerações Finais}

Aprendizagem baseada em jogos digitais é um desafio, tanto para o professor quanto para o aluno, mas com certeza o resultado obtido é promissor. Como relatado anteriormente, o trabalho realizado com os alunos do ensino médio-técnico de informática, apesar de estar em uma fase inicial, já consegue apresentar alguns bons resultados, tanto no aprendizado dos alunos quanto na motivação.

Pode-se dizer que a incorporação das tecnologias digitais à prática docente no curso é coerente às fases de apropriação e invenção, conforme o projeto ACOT (Dwyer, Ringstaf, Sandholtz, 1990), além da utilização das oito normas proposta por Tapscott (1999): liberdade, customização, investigação, integridade, colaboração, entretenimento, velocidade e inovação; que caracterizam bem a forma como os alunos aprendem.

Considerando ainda a classificação proposta por Prensky (Figura 3), percebe-se que tanto o envolvimento quanto a aprendizagem estão na dimensão alta. Os alunos são motivados a criarem seus games e o objetivo final é alcançado, pois eles aplicam o conhecimento adquirido construindo os próprios jogos digitais. Além disso, conseguem fazer uma conexão com a própria realidade (Mattar, 2010).

Existem várias iniciativas que auxiliam e incentivam professores e alunos na aprendizagem baseada em games (Alves, 2008; Mattar, 2010; MIT, 2014; Prensky, 2012; Vieira; Nörnberg; Rodrigues, 2014), mas é importante salientar que todos precisam estar envolvidos neste processo e que esta é apenas uma ferramenta para apoiar o ensino-aprendizagem.

Apesar de existir material que discuta a relação entre o ensino de games e educação, a criação de jogos digitais ainda é uma área em desenvolvimento, principalmente no Brasil. Mattar (2010) afirma, em seu livro, que é necessário criar uma mão de obra capaz de desenvolvê- 
-los, integrá-los ao design institucional e inclusive formar educadores e os próprios alunos para modelarem e criarem seus games, mesmo que mais simples.

Como isto, a ideia de implementar jogos para ensinar algoritmos e programação é recente na instituição, mas, ainda assim, observou-se uma diminuição na desistência e na reprovação nos anos iniciais; por isso, a tabela 3 apresentada no artigo continua sendo atualizada, justamente para dar prosseguimento ao trabalho desenvolvido.

Recebido em 30 de maio de 2015 Aprovado em 12 de novembro de 2015

\section{Notas}

1 Conforme Chaves (1999, p. 31) “[...] é importante lembrar que a fala, a escrita, o texto impresso são tecnologia. Os educadores usam diversas tecnologias no seu trabalho. É apenas por terem se tornado tão familiares que essas tecnologias passaram a ser transparentes, invisíveis, certamente inconspícuas".

2 Neste artigo, o termo games será usado como sinônimo para jogos digitais.

3 Educação Profissional Técnica de Nível Médio, na modalidade Integrada. Define-se como integrada: a oferta de educação profissional técnica de nível médio de forma articulada ao ensino médio, planejada de modo a conduzir o aluno à habilitação profissional na mesma instituição de ensino, efetuando-se matrícula única para cada aluno em um só turno (manhã ou tarde), podendo ser usado o contraturno para outras atividades pedagógicas previstas no plano de curso.

4 Sequência finita de regras, raciocínios ou operações, aplicada a um número finito de dados com o objetivo de solucionar problemas (Cormen et al., 2009).

5 O Projeto ACOT - Apple Classrooms of Tomorrow - foi iniciado em 1985, nos Estados Unidos, e desenvolvido em colaboração de pesquisa entre universidades e escolas públicas americanas, juntamente com a Apple Computer, tendo como objeto a inserção do uso das tecnologias no ambiente escolar, bem como o desenvolvimento de um modelo de avaliação para a utilização pedagógica dos computadores e outras tecnologias em sala de aula.

6 Jogo da empresa Big-Star, disponível em: <www.bigstarbrinquedos.com.br> (Bigstar, 2015).

7 Como o jogo é colorido, algumas referências são em relação à cor, mas neste texto foi usada a numeração dentro da figura.

8 Não houve entrada no segundo período de 2005 no turno vespertino e por isso aparecem as porcentagens zeradas em algumas células da tabela.

9 Disponível em: <https://scratch.mit.edu/> (MIT, 2014).

\section{Referências}

ALDRICH, Clark. Learning by Doing: a comprehensive guide to simulations, computer games, and pedagogy in e-Learning and other educational experiences. Hoboken: John Wiley \& Sons, 2005.

ALVES, Lynn. Relações entre os Jogos Digitais e Aprendizagem: delineando percurso. Educação, Formação \& Tecnologias, Lisboa, v. 1, n. 2, p. 3-10, nov. 2008.

112 Educação \& Realidade, Porto Alegre, v. 41, n. 1, p. 91-115, jan./mar. 2016. 
ARRUDA, Eucidio Pimenta. Fundamentos para o Desenvolvimento de Jogos Digitais. Porto Alegre: Bookman, 2014.

BARBOSA, Alexandre F. Pesquisa sobre o Uso das Tecnologias de Informação e Comunicação nas Escolas Brasileiras: TIC Educação 2013. São Paulo: Comitê Gestor da Internet no Brasil, 2014.

BEHRENS, Maria Aparecida. A Prática Pedagógica dos Professores Universitários: perspectivas e desafios frente ao novo século. São Paulo: Pontifícia Universidade Católica de São Paulo, 1995.

BIGSTAR. BigStar Brinquedos. São Paulo, 2015. Disponível em: <http://www. bigstarbrinquedos.com.br/>. Acesso em: 27 nov. 2015.

CARNIELLO, Luciana Barbosa; RODRIGUES, Bárbara Alcântara Gratão; MORAES, Moema Gomes. A Relação entre os Nativos Digitais, Jogos Eletrônicos e Aprendizagem. In: SIMPÓSIO DE HIPERTEXTO E TECNOLOGIAS NA EDUCAÇÃO, 3, 2010, Recife. Anais... Recife: 2010. Disponível em: <https://www. ufpe.br/nehte/simposio/anais/Anais-Hipertexto-2010/Luciana-Barbosa-Carniello\&Barbara-Alcantara-Gratao\&Moema-Gomes-Moraes.pdf $>$. Acesso em: 27 nov. 2015 .

CARVALHO, Caio Abitbol; OLIVEIRA, Eloiza da Silva Gomes de; SILVA, Fabiana Triani Barbosa da. Aprendizagem e Tecnologias Digitais: novas práticas, jovens aprendizes. In: COLÓQUIO INTERNACIONAL EDUCAÇÃO, CIDADANIA E EXCLUSÃO (CEDUCE), 4, 2015, Rio de Janeiro. Anais... Rio de Janeiro: 2015. Disponível em: <http://www.editorarealize.com.br/revistas/ceduce/trabalhos/ TRABALHO_EV047_MD1_SA6_ID889_04052015160046.pdf>. Acesso em: 27 nov. 2015.

CHAVES, Eduardo Oscar de Campos. Tecnologia na Educação, Ensino a Distância, e Aprendizagem Mediada pela Tecnologia: conceituação básica. Revista da Educação, Campinas, v. 3, n. 7, p. 29-43, nov. 1999.

CORMEN, Thomas et al. Introduction to Algorithms. Cambridge: MIT Press, 2009.

DE LUCA, Cristina. O Que É Inclusão Digital? In: CRUZ, Renato (Org.). O que as Empresas Podem Fazer pela Inclusão Digital. São Paulo: Instituto Ethos, 2004. P. 9-11.

DWYER, David; RINGSTAF, Cathy; SANDHOLTZ Judith. Teacher Beliefs and Practices Part I: patterns of change. Califórnia: Apple Computer Inc., 1990. Disponível em: <http://gse.buffalo.edu/fas/yerrick/ubscience/UB_Science_Education_Goes_to_School/Technology_Reform_files/ACOT_TrBeliefs1_1996.pdf >. Acesso em: 6 out. 2014 .

FREIRE, Maximina Maria. Formação Tecnológica de Professores: problematizando, refletindo, buscando... In: SOTO, Ucy; MAYRINK, Mônica Ferreira (Org.). Linguagem, Educação e Virtualidade. São Paulo: Cultura Acadêmica, 2009. P. 13-28.

FREIRE, Paulo. Pedagogia do Oprimido. Rio de Janeiro: Paz e Terra, 1983.

GRÜBEL, Joceline Mausolff; BEZ, Marta Rosecler. Jogos Educativos. Renote, Porto Alegre, v. 4, n. 2, dez. 2006.

HOWE, Neil; STRAUSS, Willian. Millennials Rising: the next great generation. New York: Vintage Books, 2000.

JENKINS, Henry. A Cultura da Convergência. São Paulo: Aleph, 2009.

KENSKI, Vani Moreira. Educação e Tecnologias: o novo ritmo da informação. São Paulo: Papirus, 2009.

Educação \& Realidade, Porto Alegre, v. 41, n. 1, p. 91-115, jan./mar. 2016. 
LÈVY, Pierre. Inteligência Coletiva: por uma antropologia do ciberespaço. Washington: Organización Panamericana de la Salud, 2004.

MATA, Eulália; PINHEIRO, Marcia; JACOB JR, Antonio. Proposta de um Sistema Lúdico para Ensino de Programação a Alunos do Ensino Médio. In: CONGRESSO BRASILEIRO DE ENSINO SUPERIOR À DISTÂNCIA (ESUD), 10, 2013, Belém. Anais... Belém: 2013. P. 1-14.

MATTAR, João. Games em Educação: como os nativos digitais aprendem. São Paulo: Pearson, 2010.

MENDONCA NETO, Valter dos Santos. A Utilização da Ferramenta Scratch como Auxílio na Aprendizagem de Lógica de Programação. In: CONGRESSO BRASILEIRO DE INFORMÁTICA NA EDUCAÇÃO (CBIE), 2, 2013, Campinas. Anais... Campinas: 2013. P. 260-269.

MIT Group. Scratch. Instituto de Tecnologia de Massachusetts: Lifelong Kindergarten on Media Lab, 2014. Disponível em: <http://scratch.mit.edu/>. Acesso em: 6 out. 2014.

MONTEIRO, Mario Antônio. Introdução à Organização de Computadores. Rio de Janeiro: LTC, 2007.

PALFREY, John; GASSER, Urs. Nascidos na Era Digital: entendendo a primeira geração dos nativos digitais. Porto Alegre: Artmed, 2011.

PAPERT, Seymour. A Máquina das Crianças: repensando a escola na era da informática. Porto Alegre: Artmed, 2008.

PELLANDA, Nize Maria Campos; SCHLÜNZEN, Elisa Tomoe Moriya; SCHLÜNZEN JÚNIOR, Klaus (Org.). Inclusão Digital: tecendo redes afetivas/cognitivas. Rio de Janeiro: DP\&A, 2005.

PEREIRA, Pryscilla de Souza; MEDEIROS, Marcos; MENEZES, José Wally Mendonça. Análise do Scratch como Ferramenta de Auxílio ao Ensino de Programação de Computadores. In: CONGRESSO BRASILEIRO DE EDUCAÇÃO EM ENGENHARIA (COBENGE), 40, 2012, Belém. Anais... Belém: 2012. Disponível em: <http://www.abenge.org.br/CobengeAnteriores/2012/artigos/104281.pdf>. Acesso em: 27 nov. 2015.

PRENSKY, Mark. Digital Natives, Digital Immigrants. Bradford: MCB University Press, 2001. Disponível em: <http://www.marcprensky.com/writing/ Prensky\%20-\%20Digital\%20Natives,\%20Digital\%20Immigrants\%20-\%20Partl. pdf>. Acesso em: 7 fev. 2015.

PRENSKY, Mark. Aprendizagem Baseada em Jogos Digitais. São Paulo: Senac, 2012. QUADROS, João Roberto; CASTANEDA, Rafael; AMORIM, Myrna; HERZOG, Guilherme; CARNEIRO, Lucas; MENEZES, Kaique; PINHEIRO, Matheus; OLIVEIRA, Daniel; OGASAWARA, Eduardo. Construção de Ambiente para Desenvolvimento de Jogos Educacionais Baseados em Interface de Gestos. Revista Brasileira de Computação Aplicada, Passo Fundo, v. 5, n. 2, p. 110-119, 2013.

ROSA, Rosemar. Trabalho Docente: dificuldades apontadas pelos professores no uso das tecnologias. Encontro de Pesquisa em Educação, Uberaba, v. 1, n. 1, p. 214-227, 2013.

SCHOCAIR, Carlos Otávio; CARNEIRO, Lucas; ALVES, Gabriel; AMORIM, Myrna; CASTANEDA, Rafael; QUADROS, João Roberto; OGASAWARA, Eduardo. Estudo de Caso do Uso de Jogos Eletrônicos na Ministração de Conceitos Pedagógicos: simulação espacial do modelo Presa-Predador de Lotka-Volterra. In: SIMPÓSIO DE INOVAÇÃO TECNOLÓGICA NA EDUCAÇÃO (LANTEC), 1, 2012, São Paulo. Anais... São Paulo: 2012. P. 1-14.

114 Educação \& Realidade, Porto Alegre, v. 41, n. 1, p. 91-115, jan./mar. 2016. 
TAPSCOTT, Donald. Geração Digital. São Paulo: Makron Books, 1999.

TORI, Romero. Educação sem Distância: as tecnologias interativas na redução de distâncias em ensino e aprendizagem. São Paulo: Senac e Escola do Futuro/ USP, 2010.

VEEN, Win; VRAKKING, Ben. Homo Zappiens: educando na era digital. Porto Alegre: Artmed, 2009.

VIEIRA, Everton; NÖRNBERG, Luiz Alessandro; RODRIGUES, Rafael. Abrindo o Jogo. Pelotas, 2014. Disponível em: <http://abrindoojogo.com.br/>. Acesso em: 27 ago. 2014.

VYGOTSKY, Lev Semenovich. Pensamento e Linguagem. São Paulo: Martins Fontes, 1991.

WARSCHAUER, Mark. Tecnologia e Inclusão Social: a exclusão digital em debate. São Paulo: Senac, 2006.

Myrna Cecília Martins dos Santos Amorim é mestre em Sistemas e Computação pelo Instituto Militar de Engenharia (2002) e Bacharel em Ciência da Computação pela Universidade Católica de Petrópolis (1998). É Doutoranda do Programa de Políticas Públicas e Formação Humana na Universidade do Estado do Rio de Janeiro (UERJ). Atualmente orienta o projeto: Desenvolvimento e avaliação de jogos computacionais no ensino-aprendizagem.

E-mail:myrnasantos@gmail.com

Eloiza Silva Gomes Oliveira possui Graduação em Psicologia e em Pedagogia, Especialização em Supervisão Educacional e Mestrado em Psicologia Escolar. Concluiu o Doutorado em Educação (Universidade Federal do Rio de Janeiro) em 1997. Atualmente é professora Associada da Universidade do Estado do Rio de Janeiro (UERJ), atuando na Graduação e no Programa de Pós-Graduação em Políticas Públicas e Formação Humana (PPFH).

E-mail: eloizagomes@hotmail.com

Joel André Ferreira Santos é Doutorando em Ciência da Computação pela Universidade Federal Fluminense. Tem atuado desde 2006 em projetos de TV digital interativa, como aluno de iniciação científica, pelo laboratório MídiaCom da UFF. É Engenheiro de Telecomunicações pela Universidade Federal Fluminense, onde recebeu duas vezes o prêmio Walder Moreira, do departamento de Engenharia de Telecomunicações.

E-mail: joel.afs@gmail.com

João Roberto de Toledo Quadros é Doutor em Ciência dos Materiais pelo Instituto Militar de Engenharia do Rio de Janeiro (IME-RJ), Mestre em Sistemas e Computação pelo IME-RJ, especialista em Docência Superior pela Faculdade Bethencourt da Silva (RJ) e graduado em Engenharia Elétrica Ênfase em Sistemas e Computação pela UERJ desde 1987. Ministra em cursos de Informática, Administração e Engenharias.

E-mail:jquadros80@gmail.com 